\title{
Elektrikli Araçlardaki EMC Problemlerinin Analizi
}

\author{
${ }^{* 1,2}$ Sunay Güler, ${ }^{2}$ Sibel Yenikaya, ${ }^{2}$ Güneş Yılmaz \\ ${ }^{1}$ TOFAŞ Türk Otomobil Fabrikası A.Ş. Arge Merkezi, Bursa Türkiye \\ ${ }^{2}$ Bursa Uludağ Üniversitesi Elektrik Elektronik Mühendisliği Bölümü, Bursa, Türkiye
}

\section{Özet}

Karbondioksit emisyonunu kısıtlayıcı yeni regülasyonlardan dolayı elektrikli araçlara olan talep gittikçe artmaktadır. Elektromanyetik uyumluluk (Electromagnetic Compatibility-EMC), yüksek gerilimli batarya ünitesi ve elektrikli tahrik sistemi bileşenlerinin konvansiyonel araç mimarisine entegrasyonu nedeniyle tasarım aşamasında değerlendirilmesi gereken en kritik konulardan biri haline gelmiştir. Bu çalışmada, otomotivde EMC standartlarından ve elektrikli araçlarda sıklıkla karşılaşılan EMC problemlerinden bahsedilmiştir.

Anahtar Kelimeler: Otomotiv, elektrikli araçlar, EMC

\section{Analysis of EMC Problems in Electric Vehicles}

\begin{abstract}
Due to new regulations that limit cardon dioxide emission, the demand for electric vehicles is being increased. Electromagnetic compatibility (EMC) has become one of the most critical issues to be evaluated during design phase on account of the integration of high voltage battery unit and electric propulsion system components into conventional vehicle architecture. In this study, EMC standards in automotive and EMC problems frequently observed in electric vehicles are mentioned.
\end{abstract}

Key words: Automotive, electric vehicles, EMC

\section{Giriş}

Elektroniğin her geçen gün hayatımıza daha fazla girmesi yaşantımızı birçok alanda kolaylaştırdığı gibi bazı sorunları da beraberinde getirmektedir. Cihazların ve sistemlerin elektromanyetik girișimin olduğu ortamda birbirlerini ve canlıları olumsuz olarak etkilemeden çalışabilmesi elektromanyetik uyumluluk (Electromagnetic Compatibility-EMC) konusunun önemini ortaya çıkarmaktadır. EMC, elektronik bir cihazın veya sistemin çevresindeki diğer cihazlar için elektromanyetik girişim oluşturmadan çalışabilmesi aynı zamanda harici girişimlerin olduğu çalışma ortamında fonksiyonelliğini hatasız yerine getirmesidir [1].

1990'ların sonuna doğru otomotiv EMC standartları oluşturulan IEC (International Electrotechnical Commission), IOS (International Organization for Standards), SAE (Society of Automotive Engineers) gibi organizasyonlar sayesinde belirlenmiştir. Araç üreticileri, tedarikçi *iletişim Yazarı: Adres: TOFAŞ Türk Otomobil Fabrikası A.Ş. Arge Merkezi, İstanbul Cad., No: 574, Osmangazi, Bursa. E-posta: sunay.guler@tofas.com.tr 
firmalardan temin ettikleri komponent ve sistemlerin komponent bazında EMC standartlarını sağlamalarını beklemektedirler. Buradaki amaç bu komponentlerin elektromanyetik girişimin yoğun olduğu araç içinde kendi fonksiyonelliklerini yerine getirdiklerinden emin olunmasıdır [2]. Fakat nihai EMC onayları, tüm komponent ve sistemlerin araç üzerine entegre edildiği araç seviyesindeki testler sonrası verilir. Üretilmiş araçlar üzerinde yapılan araç seviyesinde EMC testleri ile aracın bütününe ilișkin standartların yerine getirilip getirilmediği incelenmektedir. $\mathrm{Bu}$ testler için her OEM'in (Original Equipment Manufacturer) test laboratuvarı bulunmamakla birlikte, araç seviyesindeki EMC testleri oldukça maliyetli testlerdir. Dahası testlerden negatif sonuç alınması, bitmiş bir araç projesinde soruna ilişkin kök sebebin tespiti için tedarikçi firmaların da dahil edilmesini gerektirebilecek ciddi zaman ve para kayıplarına sebep olabilmektedir.

Son y1llarda, ADAS (Advanced Driver Assistance System) sistemlerinin araçlara girmesiyle daha da karmaşık bir elektronik sistem ağı görülmektedir. Bu sistemler sürüş güvenliği ile ilgili olduklarından, herhangi bir fonksiyonel arıza ölümcül sonuçlar doğurabilmektedir. ADAS sistemlerinin çalışması için gerekli olan araç ve çevre arasındaki etkileşim, geleneksel EMC test yöntemlerine dahil değildir. $\mathrm{Bu}$ nedenle EMC standartları yeni teknolojileri dikkate alarak güncellenmelidir [3].

Elektrikli araçlardaki yüksek gerilimle çalışan komponent ve sistemlerden dolayı geleneksel araç elektroniği mimarisi farklı bir boyuta taşınmıştır. Bazı araç uygulamalarında gerilimin $900 \mathrm{~V}$ seviyelerine çıktığ 1 görülmektedir [4]. Elektrikli tahrik sisteminlerinde, yüksek gerilim seviyelerinde hılı anahtarlama yapan komponentlerden dolayı EMC sorunları tüm arac1 etkileyebilmektedir. Ayrıca, yüksek gerilim kablo tesisatında elektromanyetik girişime karşı önlemler alınmışken, konvansiyonel araçlardaki düşük gerilim kablo tesisatında yeterli önlemlerin alınmadığı görülmektedir [5].

Elektrikli araçlarda farklı gerilim seviyelerinde çalışan komponent ve sistemler EMC konusunun hem komponent hem de araç seviyesinde dikkat edilmesi gereken önemli konulardan biri olduğunu göstermektedir. $\mathrm{Bu}$ çalışmada öncelikle otomobillerdeki EMC konularına ve standartlarına değinilecektir. Sonra otomotiv sektöründe hızla yükselme eğiliminde olan elektrikli araçlarda görülen EMC problemleri sunulacaktır.

\section{Otomotivde EMC}

Bir araç projesi tamamlandıktan sonra, seri üretim öncesi EMC homologasyon testlerini geçmesi gerekmektedir. Bu testlerden negatif sonuç alınması bitmiş bir araç projesinde ciddi zaman ve para kayıplarına sebep olmaktadır. Kök sebebin tespit edilmesinde, komponent tedarikçilerinin de dahil edilmesi gereken çalışmalar gerekebilmektedir. Bu yüzden elektronik komponent ve sistemlerin belirlenen EMC standartlarında geliştirilmesi ve araç entegrasyonu sırasında EMC konularının dikkate alınarak sürecin tamamlanması önemlidir.

Araç seviyesinde EMC sorunlarının önceden tahmin edilmesinde sayısal simülasyonlardan faydalanılmaktadır [6]. Otomotiv elektroniğinin gelişim sürecinde farklı simülasyon paketleri geliştirilmiş; ancak tümdevre üreticisinin, elektronik komponent tedarikçisinin ve otomobil üreticisinin simülasyon faaliyetlerinin bağımsız olarak devam ettiği görülmüştür. OEM, elektronik komponent üreticisi ve tümdevre üreticisi arasında EMC modellerinin oluşturulup birbirine entegrasyonu ile araç seviyesinde EMC testleri için bir öngörü yapılabilmektedir. Araç şasisinin yüksek karmaşıklığı, otomotiv EMC modellemesinde önemli sorunlardan biridir. Doğru EMC modeline sahip olabilmek için araç gövdesinin çok ayrıntılı geometrik verilerine ihtiyaç vardır. Kablo tesisatı, araç şasisi ve elektronik komponentlerin yerleşim detayları sağlandığında araç 
seviyesindeki EMC simülasyonları gerçeklenebilir. Araçlar için en büyük EMC problemleri aşağıdaki gibi sıralanmaktadır [7]:

- Bir kablo demeti içindeki teller arasında kuplaj (crosstalk),

- Kablo tesisatından çevreye ve antene olan ışınım (emission),

- Dış elektromanyetik girişime karşı elektronik komponentlerin bağışıklığ1 (immunity).

Şekil 1'de günümüz araçlarındaki karmaşık komponent ve sistem ağının bir kısmı gösterilmektedir. Farklı frekans ve gerilim seviyelerinde çalışan elektronik komponent ve sistemlerin uyum içinde çalışabilmesi için EMC konusunun dikkate alınarak tasarımların ve entegrasyonun gerçekleştirilmesi gereklidir.

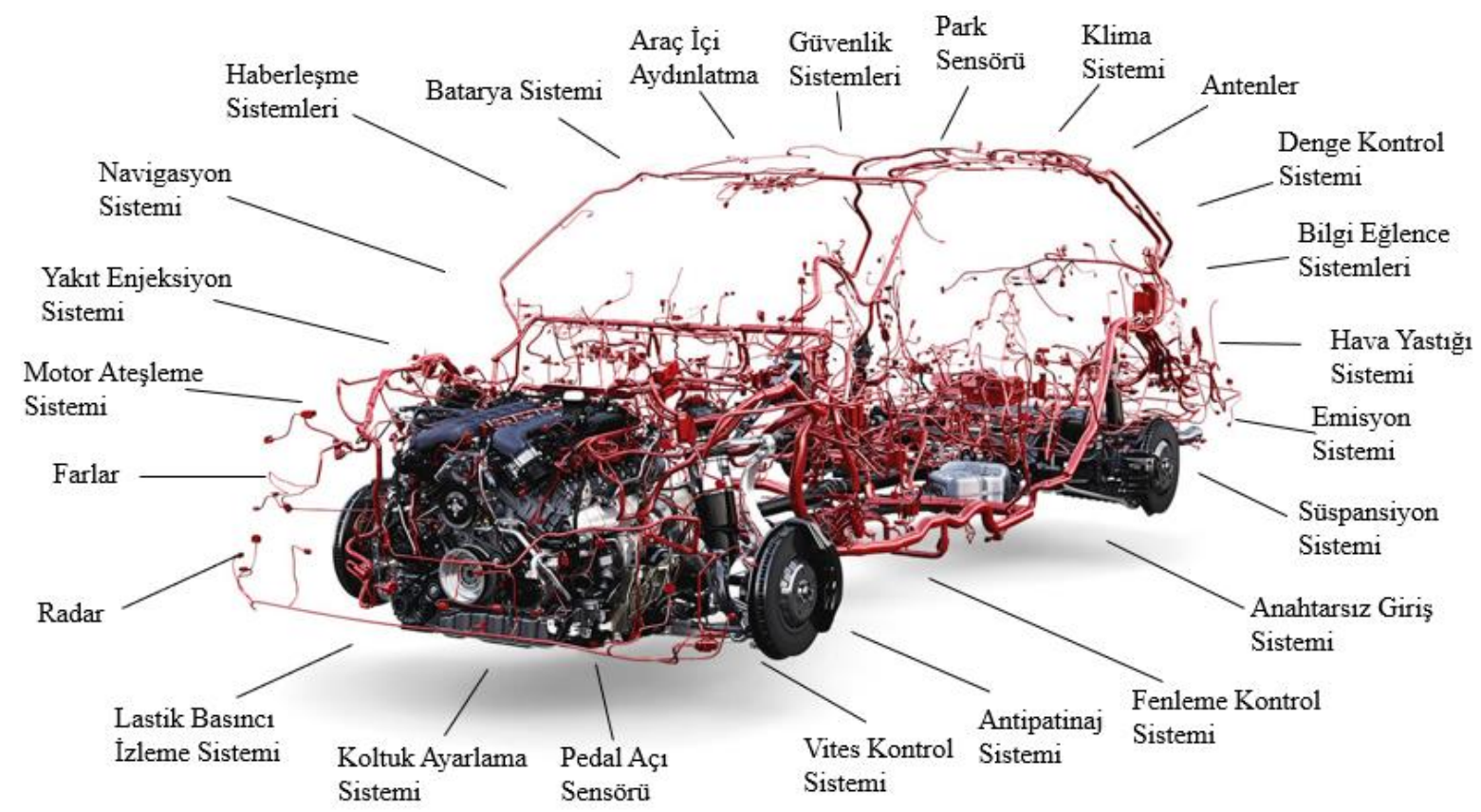

Şekil 1. Günümüz araçlarında elektrik elektronik ağı

Modern otomotiv araçları, sürücü konforunu ve araç güvenliğini arttırmak için giderek daha karmaşı kontrol sistemlerini bünyesine dahil etmektedir. İlk başta içten yanmalı motorlardaki ateşleme girişimini kontrol etmek ile başlayan otomotiv EMC çalışmaları, sürekli gelişen teknoloji ile birlikte güncelliğini korumaktadır. Otomotiv EMC standartları güncellenmekte ve yeni standartların oluşturulmasına ihtiyaç duyulmaktadır [8].

Şekil 2'de hem araç hem de komponent bazında kullanılan global EMC standartları belirtilmiştir. Bir araç projesinde OEM'ler komponent ve sistemlerin geliştirilmesinde çoğu kez ortak tasarımcı firmalar ile çalışırlar. Global EMC standartlarının yanında OEM'lerin firmalardan talep edebileceği kendilerine özgü EMC standartları ve normları olabilir. EMC standartlarına uygun komponent ve sistemler tasarlansa bile araç seri imalatı öncesinde dahi EMC problemleri ile karşılaşılabilmektedir. Bunun sebebi tüm sistemlerin ve kablo tesisatının entegrasyonu sırasında oluşacak bir problem olabileceği gibi komponentlerin yerleşimi ve hatta araç geometrisine bağli etkiler de olabilir. 


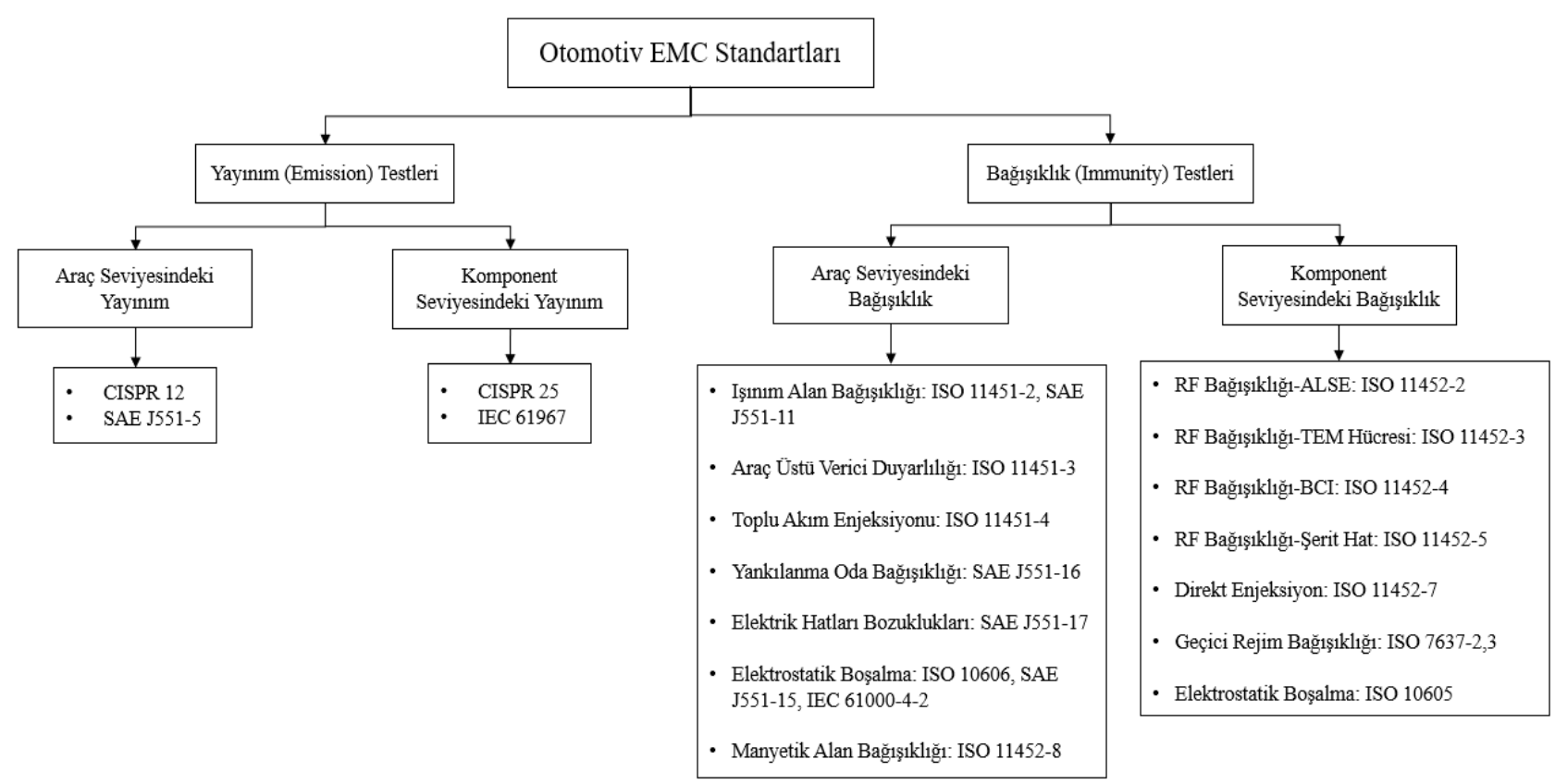

Şekil 2. Otomotiv EMC Standartları

\section{Elektrikli Araçlarda EMC}

EMC açısından, içten yanmalı motorlar yerine elektrik motorlarının kullanıldığı elektrikli tahrik sistemlerinin günümüz araçlarına entegrasyonu önemli bir zorluk teşkil etmektedir. Araç emisyon değerlerinin düşürülmesi için yürürlüğe giren katı regülasyonlar neticesinde hibrit ve elektrikli araçlara olan eğilimin arttı̆̆ görülmektedir.

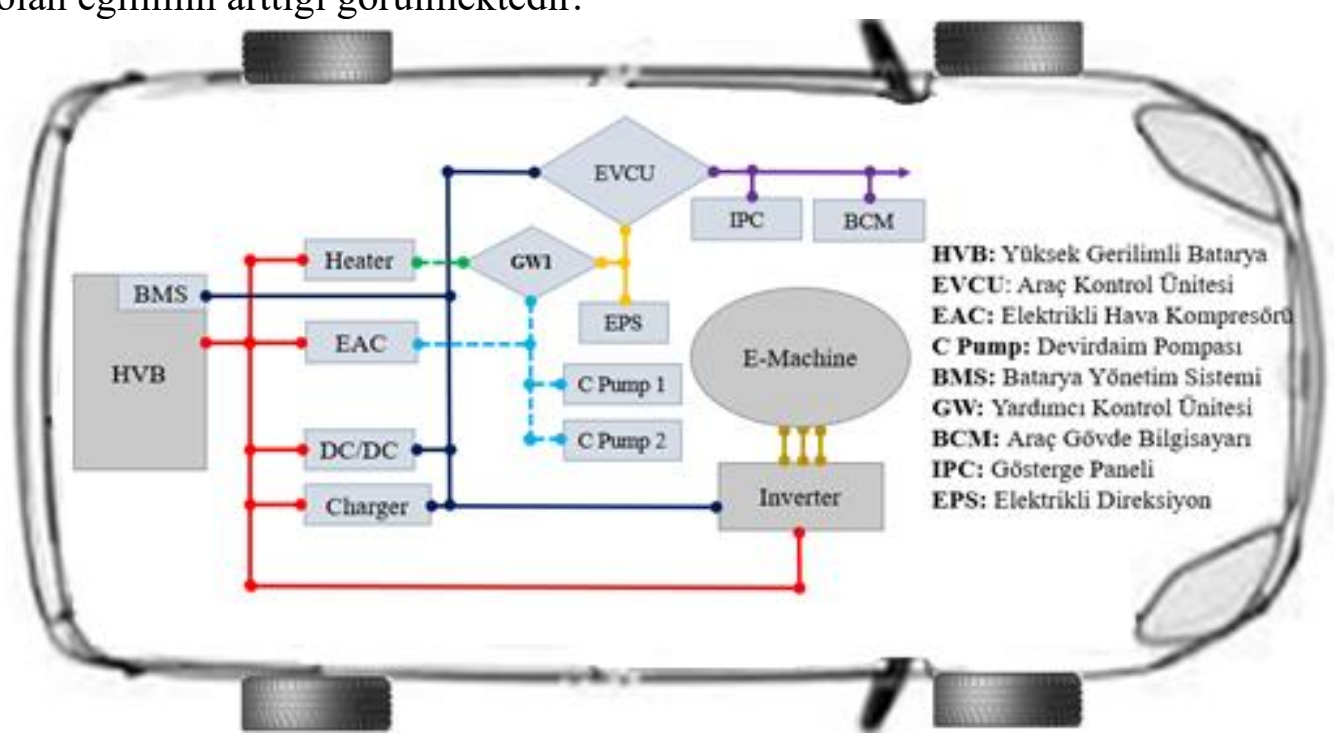

Şekil 3. Bir elektrikli araca ilişkin elektrikli tahrik sistemi [4]

Şekil 3'te tipik bir elektrikli aracın elektrikli tahrik sisteminde bulunan elektriksel ve elektronik komponentler gösterilmiştir. Elektrikli tahrik sistemi ve bileşenlerinin, EMI (Electromagnetic 
Interference) test prosedürleri ve emisyon limitleri bakımından geleneksel bir otomotiv bileşeni olarak ele alınması, önemli uyumsuzluk sorunlarına yol açacaktır. Böyle bir entegrasyonda incelenmesi gereken başlıca EMC konuları yüksek anahtarlama hızlarında çalışan invertör komponenti, elektrik motoru empedansının frekansla değişimi, elektrikli tahrik sistemi komponentlerini besleyen yüksek gerilim batarya ünitesindeki gerilim dalgalanmaları ve kablo tesisatındaki EMI korumasız tasarımlardır [9].

Elektrikli araçlarda EMC problemlerine ilişkin çalışmaların çoğunlukla yüksek anahtarlama hızlarına sahip invertör komponenti özelinde olduğu görülmektedir [10]. İnvertör komponenti, hibrit ve elektrikli araçlarda 3 fazlı elektrik motorunu sürmek, döndürmek için kullanılan güç elektroniği tabanlı bir yapıdan oluşmaktadır. Düşük ve yüksek gerilim batarya ünitelerindeki gerilim dalgalanmaları sonucu invertörün IGBT (Insulated Gate Bipolar Transistor) katındaki transistörlerde istenmeyen anahtarlamaların oluşması veya IGBT katındaki hızlı anahtarlamaların invertör komponenti içindeki ve dışındaki diğer elektronik devrelerde oluşturabileceği EMI en çok karşılaşılan problemler arasındadır.

Elektrikli mobilitenin uzun vadeli başarısı için, pazarlanabilir araçlara ek olarak güvenli şarj altyapıları sağlamak kesinlikle gereklidir. Her elektrikli mobilite ürünündeki güvenlik ve işlevsellik gereksinimleri son derece yüksek olduğundan, tüm çevresel koşullarda şarj altyapısı ile araç arasında birlikte çalışabilirlik oldukça önemlidir [11].

EMC önlemleri için güç elektroniği seviyesinde olduğu kadar, kabloların, kutuların ve giriş / çıkış filtrelerinin de korunmasına dikkat edilmelidir. Konu, elektrikli tahrik sistemlerinde çalışma gerilimlerinin, incelenen $28 \mathrm{~V}$ ile $42 \mathrm{~V}$ seviyelerinden $400 \mathrm{~V}$ ile $900 \mathrm{~V}$ arasındaki gerilim aralığına çıkması nedeniyle daha da dikkat çekicidir [12]. Elektrikli araçlarda EMC açısından bir diğer önemli nokta $12 \mathrm{~V}$ bataryalı elektronik sistemlerden yüksek gerilimli bataryalar ile çalışan komponent ve sistemlerin araca nüfuz etmesi sonucu bu karmaşık araç elektroniğinde topraklamanın çok iyi tasarlanması gerektiğidir.

Elektrikli araçlarda farklı bir EMC problemi kaynağı da PCB (Printed Circuit Board) tasarımındaki sorunlardır. Komponentler içinde yer alan kontrol devreleri analog, dijital devreler ve yükselticilerden oluşmaktadır. Bu devreler birbirlerine karşılıklı olarak müdahale eder ve yolları arasında kapasitif ve endüktif kuplajlar bulunur. Bu sorunu çözmek için güç, sinyal ve devrenin özelliği gibi faktörlere göre konumlandırma ve kablolama yapılmalıdır. Alt katmanlar kaynak ve toprak olarak kullanılır. Sensör, CAN (Controller Area Network) veriyolu ve kontrol devresi arasındaki bağlantı için optik kuplaj kullanılabilir.

Elektrikli araçlarda EMC açısından dikkate alınması gereken bir diğer konu ise kablo tesisatı ve konektörlerdir. Elektromanyetik kuplaj, kapasitif ve endüktif kuplajı büyük ölçüde azaltmak için kablo korumaları topraklanmalıdır [13].

Elektrikli araçlarda görülen EMC problemleri Şekil 4'deki gibi ana hatlarıyla sınıflandırılmıştır. Buna göre hem araç hem de komponent seviyesinde incelenmesi gereken farklı EMC problemleri bulunmaktadir. 


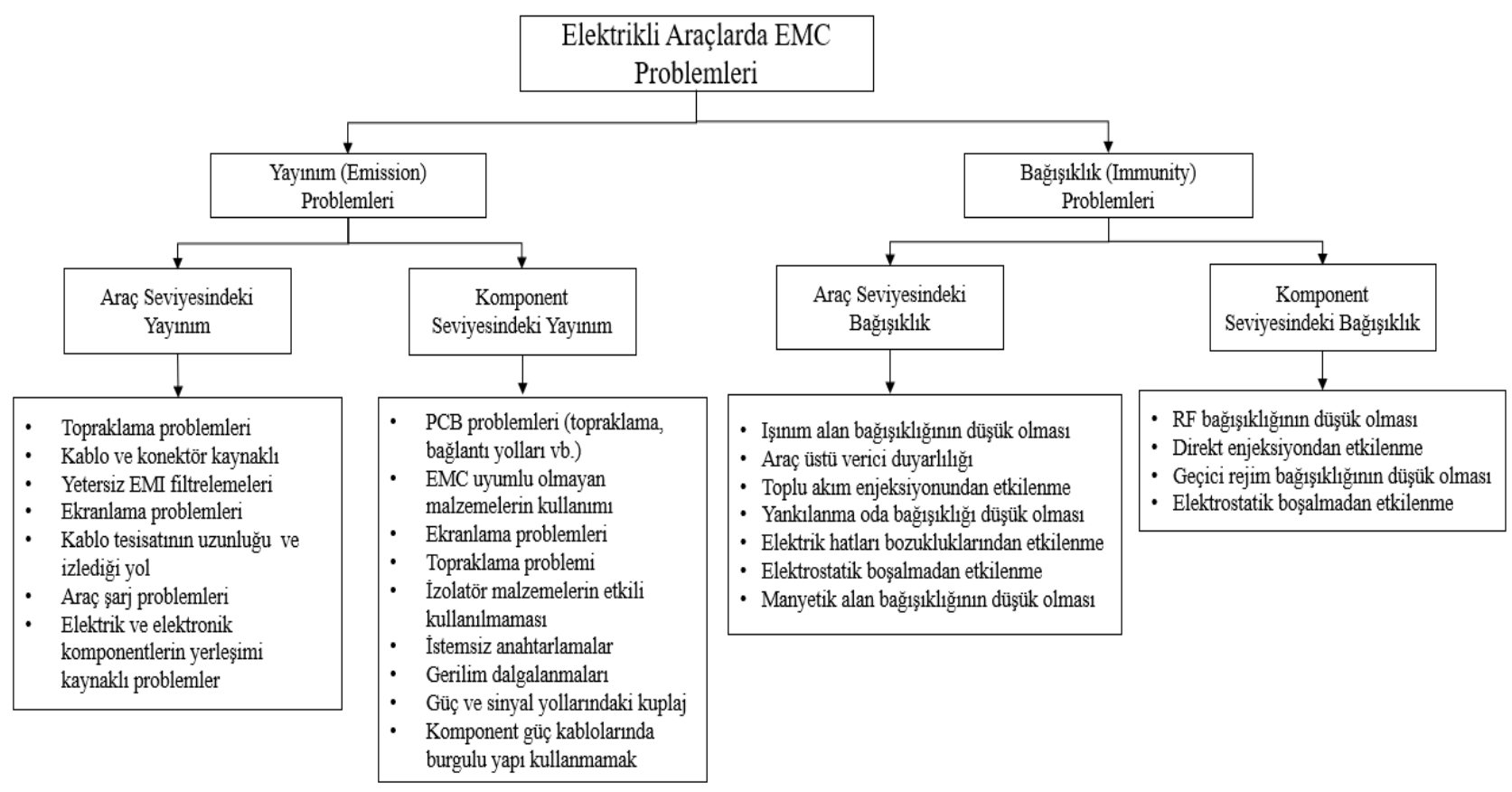

Şekil 4. Elektrikli araçlarda EMC problemlerinin analizi

\section{Sonuçlar}

Elektrikli araçlar, içten yanmalı motora sahip araçlara göre daha karmaşı ve birbirine etkisi daha fazla olan elektronik komponent ve sistemleri bünyesinde barındırmaktadır. $12 \mathrm{~V}$ batarya ünitesiyle çalışan sistemler ile yüksek gerilimli batarya tarafından beslenen komponent ve sistemlerin bir arada uyum içinde çalş̧abilmesi için dikkat edilmesi gereken önemli konulardan biri de elektromanyetik uyumluluktur.

Düşük ve yüksek gerilimli ünitelerin bir arada uyum içinde çalışabilmesi için gerek komponent gerekse araç seviyesinde EMC standartları oluşturulmuştur. Teknolojinin gelişimiyle yeni komponent ve sistemlerin araca nüfuz etmesi mevcut EMC standartlarında değişikliğe ve yeni standartların geliştirilmesinde rol oynamaktadır. Araçların, maliyeti yüksek olan EMC testlerinden başarıyla geçebilmeleri için hem komponent hem de araç seviyesinde tasarım aşamasından araç üretimine kadar olan süreçte EMC problemleri ve önleyici faaliyetler konusunda çalışmalar gereklidir.

\section{Kaynaklar}

[1] Aküner C, Dursun A. Elektromanyetik Uyum Test Yöntemleri ve Işınım Yollu Yayınım Test Örneği. e-Journal of New World Sciences Academy 2010;4:2:238-51.

[2] Zeraoulia, M et al. Electric motor drive selection issues for HEV propulsion systems: A comparative study. IEEE Transactions on Vehicular Technology 2010;556:756-64.

[3] Lei, J et al. Automotive mmWave Radar Test Developments and Challenges. $13^{\text {th }}$ European Conference on Antennas and Propagation (EuCAP) 2019. doi:10.1109/EV.2019.8892881 
[4] Güler, S, Yenikaya S, Şimşek M. EMC Design for Battery Electric Vehicle (BEV) Propulsion System. 11th International Conference on Electrical and Electronics Engineering (ELECO) 2019;286-9. doi:10.23919/ELECO47770.2019.8990410

[5] Dawson L, Rowell A, Armstrong R, Ruddle A. EMC Design Guidelines for Manufacturers of Vehicle Electric Drives. HEMIS 2014; 6.1:1-44.

[6] Ankarson P, Carlsson J. FDTD-Simulation of the Electrical Environment for Vehicles by Using CAD-Data. $3^{\text {rd }}$ International Symposium on Electromagnetic Compatibility, Beijing, China 2002.

[7] Neumayer R, Stelzer A, Haslinger F, Held J, Schinco F, Weigel R. Continuous Simulation of System-Level Automotive EMC Problems. IEEE Symposium on Electromagnetic Compatibility. Symposium Record (Cat. No.03CH37446), Boston, USA 2003.

[8] Ionescu VM. EMC Norms for Testing Electric and Hybrid Cars. Electric Vehicles International Conference (EV), Buchrarest, Romania 2019.

[9] Guttowski S, Weber S, Hoene E, John W, Reichl H. EMC Issues in Cars with Electric Drives. IEEE Symposium on Electromagnetic Compatibility. Symposium Record (Cat. No.03CH37446), Boston, MA 2003. doi:10.1109/ISEMC.2003.1236706

[10] Carlsson J, Carlberg U. On the radiation from common mode currents on cables placed over joined conducting planes commonly used in vehicles. International Symposium on Electromagnetic Compatibility, Tokyo 2014.

[11] Hirsch $\mathrm{H}$ et al. Latest development of the national and international EMC-standards for electric vehicles and their charging infrastucture. IEEE International Symposium on Electromagnetic Compatibility (EMC), Dresden 2015. doi:10.1109/ISEMC.2015.7256250

[12] Weber T. EMC filters in high voltage traction drive systems. International Symposium on Electromagnetic Compatibility-EMC 2008. doi:10.1109/EMCEUROPE.2008.4786909

[13] Carlsson J, Carlberg U. On the radiation from common mode currents on cables placed over joined conducting planes commonly used in vehicles. International Symposium on Electromagnetic Compatibility, Tokyo 2014. 